\title{
Unusual presentation of a patient with complement deficiency and immunoglobulin deficiency
}

\author{
Vaishaali Manga ${ }^{1 *}$, Donald Stark ${ }^{2}$ \\ From Canadian Society of Allergy and Clinical Immunology Annual Scientific Meeting 2013 \\ Toronto, Canada. 3-6 October 2013
}

\section{Background}

The complement system is a vital component of innate immunity. Deficiencies in any part of the complement pathway characteristically present with recurrent infections. C2 factor deficiency is the most common complement deficiency. The presentation can vary from being asymptomatic to developing recurrent infections. Thus empiric vaccinations have been recommended, despite the lack of substantial evidence to support this practice. Recently, Jonnson and colleagues revisited this controversial topic and demonstrated the importance of vaccinations in this patient population. They further established that $\mathrm{C} 2$ deficient patients can mount an immune response to vaccination, undergo class-switching and develop a 'more efficient' phagocytosis. ${ }^{1}$

C2 deficiency is inherited in an autosomal recessive pattern. Homozygotes generally present with increased severity of disease as compared to heterozygotes. Alper and colleagues state that $25 \%$ of $\mathrm{C} 2$-deficient homozygotes have increased susceptibility to severe bacterial infections. ${ }^{2}$ Furthermore, they found that these C2-deficient patients had significantly lower mean levels of IgG4 and IgA than those patients that did not demonstrate an increased susceptibility for recurrent infections.

\section{Case}

We report a case of a 59-year-old female with a history of $\mathrm{C} 2$ deficiency presenting with recurrent upper and lower respiratory tract infections. Although she received the pneumococcal vaccine, she failed to mount a response based on her post-vaccination titers. Further workup revealed a borderline low IgG. Due to her having recurrent infections and a borderline low IgG, the patient was started on subcutaneous immunoglobulin (SCIG) therapy as a trial. While on the treatment, she did not develop any new infections.

\section{Discussion}

In the cohort by Jonnson, post-vaccination $\mathrm{C} 2$ deficient patients mounted a good response to vaccination along with a 'more efficient' phagocytosis via increased opsonin production secondary to a possible $\mathrm{clq}$ dependent C2-independent pathway [1]. This pathway may not be effectively activated in post vaccinated $\mathrm{C} 2$ patients who are IgG deficient because of the role IgG plays in the c1q dependent pathway. Therefore, $\mathrm{C} 2$ deficient patients that have a concomitant immunoglobulin deficiency may respond differently to vaccination than the $\mathrm{C} 2$ deficient patient with normal immunoglobulins. We postulate that our patient did not respond to antigenic stimulations because she may fall in the $25 \% \mathrm{C} 2$ deficient homozygous category in which the IgG levels are decreased [2].

\section{Conclusion}

Further studies are requires to determine the effectiveness of vaccination in these two different $\mathrm{C} 2$ deficient patient populations and to help guide vaccination protocols.

\footnotetext{
Authors' details

${ }^{1}$ Department of Internal Medicine, Memorial University, St. John's, Newfoundland and Labrador, A1B3V6, Canada. ²Department of Clinical Immunology and Allergy, University of British Columbia, Vancouver, British Columbia, V6Z1Y6, Canada.
}

\footnotetext{
* Correspondence: vmanga@munmed.ca

'Department of Internal Medicine, Memorial University, St. John's,

Newfoundland and Labrador, A1B3V6, Canada

Full list of author information is available at the end of the article
} 


\section{References}

1. Jonsson, et al: Vaccination against encapsulated bacteria in hereditary C2 deficiency results in antibody response and opsonization due to antibody-dependent complement activation. Clinical Immunology 2012, 144:214-227.

2. Alper, et al: Immunoglobulin deficiencies and susceptibility to infection among homogyzotes and heterozygotes for C2 deficiency. Journal of Clinical Immunology 2003, 4:297-305.

doi:10.1186/1710-1492-10-S1-A39

Cite this article as: Manga and Stark: Unusual presentation of a patient

with complement deficiency and immunoglobulin deficiency. Allergy,

Asthma \& Clinical Immunology 2014 10(Suppl 1):A39.

Submit your next manuscript to BioMed Central and take full advantage of:

- Convenient online submission

- Thorough peer review

- No space constraints or color figure charges

- Immediate publication on acceptance

- Inclusion in PubMed, CAS, Scopus and Google Scholar

- Research which is freely available for redistribution

Submit your manuscript at www.biomedcentral.com/submit
Ciomed Central 